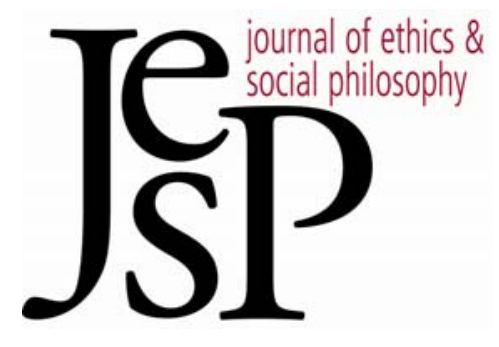

\title{
“Ought" and the Perspective of the Agent
}

By Benjamin KieseWetter

Journal of Ethics $\&$ Social Philosophy

Vol. 5, No. 3 | OCTOBER 2011

URL: WWW.JESP.ORG COPYRIGHT @ BENJAMIN KIESWETTER 2011 


\title{
"Ought" and the Perspective of the Agent
}

\author{
Benjamin Kiesewetter
}

I

MAGINE A DOCTOR WHO IS FACED with a patient's disease that she knows will lead to death unless treated shortly. ${ }^{1}$ Two possi-

ble treatments are available: A and B. After careful consideration of the available evidence, the doctor concludes that treatment $A$ will cure the patient, and B will kill him. Unbeknownst to her, however, in fact treatment B is the cure, while A will lead to the patient's death. What ought the doctor to do: give $\mathrm{A}$ or give $\mathrm{B}$ ?

Let us call facts about a person's beliefs, knowledge or evidence facts about that person's perspective. We may then ask more generally: Does what an agent ought to do depend on the agent's perspective, or is it perspective independent? Objectivists about "ought," such as G. E. Moore and J. J. Thomson, claim that "ought" is independent of the agent's perspective. ${ }^{2}$ Hence, they would hold that the doctor ought to give treatment $\mathrm{B}$ - the one that in fact cures the patient. Perspectivists like H. A. Prichard and W. D. Ross, on the other hand, believe that "ought" depends on the perspective of the agent - a view that is sometimes spelled out in terms of the agent's actual beliefs, and sometimes in terms of the evidence available to the agent. ${ }^{3}$ Both of these versions of perspectivism hold that the doctor ought to give A, not B.

\footnotetext{
${ }^{1}$ This is a modification of an example by Jackson (1991, pp. 462-63) that I will return to below. I assume that there is no reason for the doctor not to try to help the patient.

2 See Moore (1969/1912, pp. 80-82); Thomson (1986/1983). Note that Thomson slightly modifies her view in her $(2008,187-99)$, but remains opposed to the idea that "ought" depends on the agent's perspective. See Bykvist (unpublished) and Graham (2010) for two recent defenses of objectivism, though both limit their discussion to moral obligation and leave open how it relates to the practical ought-claims at issue here. Many philosophers subscribe to objectivism about normative reasons rather than "oughts" - a view entailed by full-information accounts of reasons such as Smith (1994) and Williams (1981a/1979, esp. 102-03). It is an interesting question, which I shall not discuss in this paper, how views about the perspective dependence of "ought" relate to views about the perspective dependence of reasons. On the plausible assumption that "ought" implies "most reason," it seems natural to suppose that both concepts are perspective dependent to the same degree. However, it is possible to think of perspectival facts as "exclusionary reasons" (cf. Raz (1975) pp. 35-48) that prevent (nonetheless existing) perspective independent reasons from contributing to what one ought (or has most reason) to do. The result would be a perspectivist view about "ought" (and "most reason") combined with objectivism about reasons.

3 In phrasing the issue in terms of perspective dependence, I follow Gibbons (2010, 335). What I call "perspectivism" is often referred to as "subjectivism," but I think it is appropriate to reserve the latter term for a belief-relative view only. Belief-relative perspectivists include Jackson (1991, esp. 464-65); Prichard (2002a/1932); and Ross (1939, 146-67). Evidence-relative perspectivists include Andric (forthcoming); Dancy (2000, ch. 3); Gibbons (2010); Robertson (2011); Scanlon (2008, 47-52); and Zimmerman (2008). Some of these authors focus on reasons or moral duties rather than "oughts," but I take it that they would all understand their claims as extending to the practical ought-claims that I am concerned with.
} 
Others again try to solve the puzzle by distinguishing different senses of "ought." According to them, all that we can say is that the doctor ought to give $\mathrm{A}$, relative to her perspective, and that she ought to give $\mathrm{B}$, relative to all the facts. I am willing to concede that it might be useful to speak of what an agent ought to do relative to certain considerations, and that different qualified notions of "ought" might be important in their own right. Nevertheless, I believe that there is a substantial question at issue between objectivists and perspectivists when it comes to what might be called the "overall ought" of practical deliberation. This is the concept involved in the deliberative question, "What ought I to do?" (or "What should I do?") and deliberative conclusions of the form, "I ought to $\phi$ " (or "I should ф"). (I take "ought" and "should" to be equivalent, but for simplicity's sake, I will mostly use "ought" in what follows.) Practical conclusions of this sort are supposed to guide rational decision-making and action directly. In other words, the "ought" at issue is the one that is appealed to in the common idea that it is irrational, or akratic, not to intend what one believes one ought to do. ${ }^{5}$ Now, in order to make a rational decision guided by a belief that one ought to do something, one needs a univocal concept of "ought" that figures in such beliefs. It is perfectly consistent to believe, "I ought to $\phi$, relative to X," and, "I ought not to $\phi$, relative to Y," but one cannot rationally intend both to $\phi$ and not to $\phi$. There must be one sense of "ought," the belief in which is the relevant one for decision-making. We need to be able to judge, "I ought to $\phi$, full stop." At any rate, this is what I shall assume in the following discussion.

The concept that is (inter alia) used in such deliberative conclusions is sometimes called the "practical ought." I think it is natural to consider the practical "ought" as the central, unqualified sense of "ought" and regard all other "oughts" as qualified senses. ${ }^{7}$ This claim, however, will not function as a substantial assumption of the argument. This paper is about the question of whether the practical "ought" depends on perspec-

${ }^{4}$ Ewing (1947, 112-44); Feldman (1988); Gibbard (2005, 340-41); Jackson (1991, 471 72); Oddie and Menzies (1992, 512); Parfit (2011, 150-64); J. Ross (2006, 167-76); Schroeder (2009); Smith (2008, 252-61); and Wedgwood (2003) all introduce different senses of "ought," though some of them accept the dominance of one or more of these senses. Alternatively, but in the same spirit, ought-statements are sometimes taken to be elliptical, i.e., claimed to be meaningless unless they at least implicitly refer to a particular body of information.

5 This is what Broome calls the rational requirement of "enkrasia" (unpublished, 17273); see below for more on this.

${ }^{6}$ E.g., by Williams $(1981 b, 118)$. The term is somewhat misleading: What is "practical" about this "ought" is that its function is to directly guide our responses, not that these responses are actions rather than, e.g., beliefs.

${ }^{7}$ Here, I follow Broome (unpublished, 20), who claims that the central sense of "ought" is the one figuring in the beliefs that are subject to the requirement of "enkrasia"; a view that is also shared by J. Ross (forthcoming). I also sympathize with Davidson's view (1980/1969, esp. pp. 38-39) that judgments concluding deliberation must be unqualified (or "unconditional," as he puts it) in order to be practical (although he takes the conclusion of a deliberation to be a betterness-judgment rather than an ought-judgment). 
tive, and I will refer to this concept by using the word "ought" without qualification only for the sake of convenience. Against this background, we can understand objectivists and perspectivists as disagreeing about the question as to which of the qualified senses of "ought" that are relativized to a certain body of propositions (such as the body of all true propositions, all believed propositions or the propositions that constitute the agent's evidence) provides the correct truth conditions for the practical "ought":

Objectivism: A ought to $\phi$ if, and only if, A ought to $\phi$ relative to all facts. ${ }^{8}$

Belief-relative perspectivism: A ought to $\phi$ if, and only if, A ought to $\phi$ relative to A's beliefs.

Evidence-relative perspectivism: A ought to $\phi$ if, and only if, A ought to $\phi$ relative to the evidence available to A. ${ }^{9}$

The aim of this paper is to defend a version of perspectivism, but I will be concerned with the evidence-relative view only. The belief-relative (or "subjective") view is problematic for several reasons; for example, it seems to entail that one can escape an ought-claim if one does not believe an inconvenient truth one has overwhelming evidence for. A detailed discussion of this view, however, is beyond the scope of this paper. Here I will simply assume that a plausible perspectivist position will be spelled out in terms of evidence, i.e., in terms of whatever it is that justifies or warrants belief (and disbelief), rather than what is actually believed. ${ }^{10}$

${ }^{8}$ It might be argued that epistemic facts (facts about A's perspective) need to be excluded from the facts relative to which "ought" is determined according to objectivism. For if what the doctor ought to do could be relative, e.g., to both the fact that pill B cures and the fact that the doctor believes that pill B kills, it would not be clear whether objectivism actually entailed that the doctor ought to give the pill that in fact cures - which was the intuitive starting point of the position. On the other hand, the general exclusion of epistemic facts would have extremely implausible consequences; e.g., if a lack of knowledge could not play any role in determining what we ought to do, it would seem that we never ought to learn anything. As I see it, the idea of weighing considerations concerning a particular state of affairs against considerations concerning A's perspective about that state of affairs does not make much sense to begin with. Therefore, I will assume that once a fact concerning a particular state of affairs is taken to play a role in the determination of whether A ought to $\phi$, it cannot be trumped by a fact concerning A's perspective on that state of affairs. This assumption ensures that objectivism entails that the doctor ought to give the pill that in fact cures and still allows that objectivists can account for the relevance of epistemic facts in certain other cases.

${ }^{9}$ Since A's perspective can be misleading with respect to what actions A can perform, it seems that perspectivism is in tension with the principle that "ought" implies "can." In response, perspectivists could either understand the dispute as ranging over options available to A, or else suggest that "ought to act" can be reduced to "ought to intend." For the sake of simplicity, I ignore these complications in what follows.

${ }^{10}$ I think of the evidence available to a person as a certain body of facts that this person would take into account if she were employing her rational capacities appropriately, but for my purposes I can stay neutral with respect to what exactly evidence consists in. Note that the evidence-relative view, in contrast to (at least the most natural interpretation of) the belief-relative view, is compatible with the thesis that normative reasons are facts (which, in other contexts, is sometimes called “objectivism," e.g., in Dancy (2000)). 
I shall begin, in section I, by setting out the debate between objectivists and perspectivists. Drawing on an example by Frank Jackson and the literature that has arisen from the discussion of this and structurally similar examples, I motivate perspectivism by showing that, unlike objectivism, it provides us with a plausible account of normative guidance. In the main part of the paper (sections II-VI), I discuss a set of problems which many, including myself, take to be the most serious challenge to perspectivism: First, if what an agent ought to do depends on her limited information, how can a better-informed adviser give good advice to this agent in terms of what the agent ought to do? Second, how can we understand an agent's seeking new evidence, or an adviser's sharing evidence not yet available to the agent, as ways of finding (or helping to find) an answer to the agent's deliberative question, "What should I do?" if the correct answer to that question depends on the agent's perspective? My aim is to develop a perspectivist account that answers these questions by paying close attention to the role of time in the truth conditions of oughtjudgments. In section VII, I conclude with a summary of the results achieved.

In response to the above-mentioned problems for perspectivism, some philosophers have recently argued for relativist theories of "ought," according to which what an agent ought to do does not depend on the perspective of the agent herself, but on the perspective of the speaker, or even the assessor, of the ought-statement. ${ }^{11}$ Such accounts raise their own problems, for example by allowing for a multitude of practically incompatible truths about what an agent ought to do at a given time, but a discussion of these views lies beyond the scope of this paper. However, a defense of perspectivism - the view that the practical "ought" invariantly relates to the perspective of the agent - will help to undermine the need for such relativist accounts, which are generally motivated by the supposed failure of non-relativist accounts to resolve the problems in question.

\section{Objectivism vs. Perspectivism}

When we make up our mind about something, we normally take the object of our thinking to be independent of our perspective on it. Objectivists hold that things are not any different when it comes to thinking about what we ought to do. As a consequence, an agent's belief that she ought to do something could be perfectly justified by her evidence - and yet false. Perspectivists, on the other hand, claim that the truth we seek in practical deliberation does itself depend on our evidence. Some motivate this view by drawing attention to the normative relevance of epistemic risk; others by pointing to the plausible connection between what we ought to do and what we are responsible for doing. The most pressing

${ }^{11}$ See Björnsson and Finlay (2010); Kolodny and MacFarlane (2010, unpublished). The former view is sometimes referred to as "contextualism," and the latter as "relativism," but both views have contextualist as well as relativist aspects. See also Henning (unpublished) for a contextualist treatment of the issues discussed here. 
problem for objectivism, however, is that it cannot account for guidance under conditions of uncertainty. It is here that perspectivism seems overwhelmingly more attractive than objectivism. Consider the following example by Frank Jackson:

\begin{abstract}
Jill is a physician who has to decide on the correct treatment for her patient, John, who has a minor but not trivial skin complaint. She has three drugs to choose from: drug A, drug B, and drug C. Careful consideration of the literature has led her to the following opinions. Drug A is very likely to relieve the condition but will not completely cure it. One of drugs B and $\mathrm{C}$ will completely cure the skin condition; the other though will kill the patient, and there is no way that she can tell which of the two is the perfect cure and which is the killer drug. What should Jill do? $?^{12}$
\end{abstract}

As Jackson points out, objectivists give the intuitively false answer to that question. Since it is a matter of fact that one drug (either B or C) completely cures the patient, objectivism entails that Jill ought to give that drug. Objectivists therefore have to say that Jill either ought to give drug $\mathrm{B}$ or ought to give drug C. But giving $\mathrm{B}$ and giving $\mathrm{C}$ both involve a 50 percent epistemic risk of killing Jill's patient, John, a risk that is clearly not outweighed by the 50 percent chance of curing John's minor skin complaint. No doubt, the only responsible thing for Jill to do is to give drug A, but unless we take into account her perspective, we cannot say that she ought to give A. Hence, perspectivism is much better equipped to deal with the example than objectivism. ${ }^{13}$

A common reply on behalf of objectivism is to introduce a distinction between what agents ought or ought not to do, on the one hand, and what they are to be praised or blamed for, on the other. ${ }^{14}$ Objectivists agree that it would be unreasonable or blamewortby for Jill not to give drug A, but maintain that it simply does not follow that she ought to give that drug.

The problem with this reply is that it leaves entirely open how Jill could be guided to do what everyone agrees is the only reasonable thing to do. Traditionally, objectivists have assumed that we could be guided by our justified (but possibly false) beliefs about what we objectively ought

\footnotetext{
12 Jackson (1991, 462-63). Regan (1980, 265) presents a structurally equivalent case, as do Parfit's mine-shafts example $(2011,159)$ and J. Ross's three-envelope problem $(2006$, 174).

${ }^{13}$ Jackson is concerned with consequentialist versions of objectivism and perspectivism only, but his point applies independently of that supposition. As Jackson also shows, not every possible perspectivist account entails that Jill ought to give A: The view that one ought to maximize expected value does, but the view that one ought to do what is subjectively most likely to maximize actual value does not, for example. I want to stay neutral between substantial accounts of perspectivism, but I am happy to exclude all those that do not entail that Jill ought to give A.

${ }^{14}$ See, e.g., Graham (2010, 93-94); Moore (1969/1912, 81-82); Thomson (2008, 191). Scanlon also maintains a distinction between wrongness and blameworthiness, but holds a perspectivist view about "ought" nonetheless (2008, 47-52).
} 
to do. ${ }^{15}$ But Jackson's example shows that this is not true, for Jill knows that giving $\mathrm{A}$ is definitely not what she objectively ought to do. It thus seems that the objective "ought" cannot guide our decision-making in cases of uncertainty, and thus cannot be the practical "ought" that we employ in deliberative conclusions.

Things seem even worse for objectivism once we acknowledge the crucial connection between practical ought-judgments and rational intentions, as especially John Broome has emphasized. ${ }^{16}$ For it seems that Jackson's example can be constructed in such a way that an objectivist doctor has to believe that she ought not to give A, since omitting to give A is a necessary means for doing what she objectively ought to do. Given that rational agents intend in accordance with their ought-judgments, as is widely acknowledged, ${ }^{17}$ it follows that a rational objectivist has to intend not to give $\mathrm{A}$, and is thus forced, on pain of irrationality, to impose a 50 percent epistemic risk of death on a person in order to gain a 50 percent chance of curing an otherwise harmless disease. In other words, objectivist views not only fail to provide guidance, they even seem to misguide agents towards making extremely irresponsible decisions. ${ }^{18}$

These objections against objectivism seem to me decisive. At any rate, the fact that perspectivism can handle the case of Jill much better than objectivism is a good reason to consider perspectivism as a potentially superior view. But perspectivism faces its own challenges. In particular, it has problems accounting for phenomena in which the use of "ought" is geared to evidence that is better than the evidence currently available to the agent. In the following sections, I set out to meet this challenge by developing a perspectivist account that captures the phe-

\footnotetext{
${ }^{15}$ Cf. Moore (1969/1912, 82).

${ }^{16}$ See Broome (unpublished, 28-36). J. Ross (forthcoming) defends an argument against objectivism on similar grounds.

17 The view that a mismatch of practical normative judgments and intentions constitutes irrationality is often considered to be uncontroversial (e.g., by Coates, forthcoming). At any rate, it is shared by a variety of philosophers who disagree about many other questions, among them Broome (unpublished, 172-73); Davidson (1969, 41); Korsgaard (1986, 11); Kolodny (2005, 521); Parfit (2011, 113); Scanlon (1998, 25); Smith (1994, 148); and Williams (1981a/1979, 107). Arpaly appears to be an exception, but her arguments seem to be directed against a particular conception of "enkrasia," and as she notes herself, she actually endorses the view "that every agent who acts against her best judgment is, as an agent, less than fully rational" $(2000,491)$. Note that I remain neutral, here, on the question of whether the connection between normative judgments and intentions takes the form of a requirement, whether such a requirement takes wide or narrow scope and whether it is itself something that we ought, or have reason, to satisfy (for a discussion of this, see Kolodny (2005)).

18 Note that this conclusion extends to any view that invariantly relates "ought" to a body of information that includes information not available to the agent, even if it is not the body of all true propositions. Thomson, after championing objectivism for decades, has recently argued (roughly) that "ought" relates only to those facts that are (or could be) available to a human being $(2008,195)$. A doctor believing this view, however, would be forced, on pain of irrationality, to make an extremely irresponsible decision if she knew that some human being (which one is not accessible to her) knew whether B or $\mathrm{C}$ is the cure.
} 
nomena in question. I will start by discussing the problem that cases of advice pose for perspectivism.

\section{The Problem of Advice}

When people ask themselves what they should do, they sometimes ask others for advice. It is thus natural to assume that advice typically seeks to answer the deliberative question for the agent; it shares with deliberation the topic of what the agent ought to do in the practical sense. ${ }^{19}$ Perspectivism claims that what an agent ought to do in this sense is relative to the agent's perspective. To recall the case of Jill, perspectivism claims that Jill ought to give drug $\mathrm{A}$ if she has no evidence whether $\mathrm{B}$ or $\mathrm{C}$ in fact cures or kills the patient. But now let us suppose that a third person enters the stage, one who knows that $\mathrm{C}$ is the cure and is able to disclose this information to Jill. Naturally, the third person will give Jill the following advice: "You ought to give C!" Indeed, it seems that this would be the only good advice a person with such knowledge could give. Yet on the face of it, perspectivism entails that this adviser's statement would be literally false, since relative to Jill's evidence at the time of the advice, she ought to give A and not C. Apparently, then, perspectivism entails that a better-informed adviser cannot truly give the only good advice in the situation described. Call this the problem of advice. ${ }^{20}$

The problem of advice poses a serious challenge for perspectivists: When Jill asks the adviser, "What ought I to do?" it seems that she does not want a report about what her current evidence already tells her to do, but rather hopes for something beyond that. And it would be more than natural to suppose that the better-informed adviser will answer her question correctly - and in the very sense that Jill was after when asking for advice - when he makes his answer dependent on his better knowledge and not on the evidence of the agent. On the face of it, however, it seems that perspectivism cannot account for this phenomenon.

A common reply on behalf of perspectivism maintains that by giving advice in accordance with superior information, advisers anticipate the truth of their own statement in the nearby future. In the process of advising Jill to give $\mathrm{C}$, the adviser thus changes Jill's evidence and thereby makes it true that she ought to give C. According to this suggestion, saying, "You ought to give C," is a bit like saying, "You want to go left at the

\footnotetext{
${ }^{19}$ I take this characterization from Kolodny and MacFarlane (unpublished), to whom the discussion of this section is very much indebted. See also Williams (1995/1989, 40): "advice aims to offer something as a candidate for a deliberative conclusion." The crucial point is that advice seeks to answer the question that agents would ask in (and thus has the same object as) deliberation; it is not necessary that agents actually deliberate about it.

${ }^{20}$ For this line of objection to perspectivism see, e.g., Kolodny and MacFarlane (2010, 119-20); Thomson (2008, 187-91). I stipulate in all adviser cases that the adviser knows (and not merely justifiably believes) that $\mathrm{C}$ is the cure, because the problem of advice is driven in part by the intuition about the truth of an ought-statement made by a betterinformed person.
} 
light," when we are being asked for directions - not literally true, but anticipating a truth that in part will be brought about by the utterance itself (or by accompanying elucidations). ${ }^{21}$

While I agree that the adviser's interference in the situation and the transmittance of information plays a crucial role for the understanding of the problem of advice, I believe that this suggestion is a confession of failure rather than a solution to the problem. The reply admits that the adviser's statement is strictly speaking false at the time it is made. It thus cannot account for the intuition that an adviser gives the correct answer to the question an agent is asking when he grounds his advice in his better knowledge, but instead reduces his answer to a merely rhetorical device. A non-literal interpretation of "You want to go left at the light" seems unproblematic, since advice clearly does not aim at telling the agent what he already wants to do. A non-literal interpretation of "You ought to give C," on the other hand, comes at a high price, since it must dismiss the plausible idea that advice typically aims at providing an answer to the question agents ask in deliberation.

Similar worries apply to responses to the problem of advice that allude to different notions of "ought." 22 I said in the beginning that the "ought" figuring in deliberative conclusions cannot be ambiguous between different qualified notions of "ought." For the time being, this leaves open the possibility of other senses of "ought" that do not compete with the deliberative "ought." Perhaps there is a genuine second- or third-personal "ought" that is different from the notion employed in deliberation. We can imagine this "ought" to be coextensive with the objective "ought," but more plausibly it will relate to the evidence of the second or third person. ${ }^{23}$ On this construal, a perspectivist adviser can truly say, "You ought to give C," meaning to state that Jill ought, relative to his - the adviser's - evidence, give $\mathrm{C}$, which is compatible with the claim that Jill ought to give $A$ in the practical sense.

But while this suggestion preserves the truth of the adviser's statement, it does so only by depriving the adviser and the agent of a common subject matter. As a result, we are forced to give up the natural idea that advisers seek to answer the agent's question, "What ought I to do?" for them. For according to the suggestion, the adviser is concerned with what the agent ought to do relative to the adviser's evidence, while this is not the concern of the agent.

As Niko Kolodny and John MacFarlane have argued, the suggestion also stands in conflict with the phenomena of disagreement and retrac-

${ }^{21}$ Cf. Prichard (2002a/1932, 94); Ross (1939, 152-53). For a recent version of this reply, see Gibbons (2010, 356), who is also the source of the analogy to sentences of the form, "You want to go left at the light."

22 See, e.g., Jackson (1991, 471-72).

${ }^{23}$ It is more plausibly relative to the evidence of the other person because that other person can find herself in the same informational state as the doctor did before, and it would be irresponsible of her to give advice that could only be followed by imposing a 50 percent risk of death on the patient. 
tion that we find in these cases. Suppose that Jill considers her options and concludes, "I ought to give A." Knowing that C provides the cure, an adviser could express disagreement with this conclusion, maintaining, "No! You ought to give C!" But if he meant "ought" in a sense different from the one employed by the agent, then there would not be any disagreement between them. Moreover, it seems that Jill could retract her earlier statement, holding, "Oh, you're right - what I really ought to do is give C." Again, this would not make much sense if both original statements addressed different issues. If the dialogue we imagined is not an expression of complete confusion, it seems it must have one sense of "ought" as a common subject - the very sense of "ought" that an agent is after when he asks the deliberative question, "What ought I to do?"24

To sum up, perspectivists seem forced to accept that an adviser who grounds an ought-statement in his better knowledge either utters a sentence that is literally false or talks past the agent by employing a different notion of "ought." In both cases, they have to reject an attractive conception of advice and its engagement with deliberation that emerges naturally from linguistic observations. In the next section, I will put forward and defend a solution to the problem of advice that avoids these results.

\section{Ought and Time (i)}

In order to solve the problem of advice, we need to take account of time. First, since one can violate an ought-claim by performing the required action too late or too early, it follows that statements like "A ought to $\phi$ " must implicitly refer to time; they must be understood as stating that A ought to $\phi$ at $t$. Second, since an agent's evidence changes over time, perspectivists need to clarify what evidence they are referring to: the evidence available at the time of the ought-judgment or the evidence available at the time of the action. In discussing the problem of advice, we have implicitly taken for granted the former option, but as I shall argue in this section, the latter option not only provides an attractive solution to our problem, it is also the more plausible view for independent reasons. Hence, I suggest the following interpretation of perspectivism:

Static perspectivism: A ought to $\phi$ at $t$ if, and only if, A ought to $\phi$ at $t$ relative to the evidence that is available to $\mathrm{A}$ at $t$.

I call this view "static" because according to it, truths of the form "A ought to $\phi$ at t" are always fixed by the agent's evidence at $t$, and thus independent of the different bodies of evidence at different points of

24 Cf. Kolodny and MacFarlane (unpublished). In defense of different notions of "ought," Björnsson and Finlay (2010, 17-25) present an interesting solution to the disagreement and retraction cases. Whether or not their solution is convincing, however, they ultimately have to deny the plausible idea that advice, at least in part, seeks to answer the deliberator's question, "What should I do?" 
time at which someone judges that $\mathrm{A}$ ought to $\phi$ at $\mathrm{t}^{25}$ As a consequence of this view, when I judge now that I ought to do something later, the truth of my judgment will not depend on the evidence available to me now, but on the evidence that will be available at the time at which I am supposed to act. The reader will probably already anticipate how the static view helps the perspectivist with the problem of advice. A betterinformed adviser can truly state, "You ought to give C," since what the agent ought to do is relative to the evidence available to her at the time of the action, and by that time she will indeed have evidence relative to which she ought to give $\mathrm{C}$ - because the adviser will have told her that $\mathrm{C}$ is the cure. ${ }^{26}$

This solution bears some resemblance with the one I rejected earlier on the ground that it reduces advice to a merely rhetorical device. But in contrast to that solution, the static view allows for the literal truth of the adviser's statement and thus ensures that advisers can take their advice to be a straightforward answer to the agent's deliberative question, "What ought I to do?" - for this question is now itself understood as reaching beyond the current state of evidence of the agent, aiming rather at the evidence that can be collected until the decision has to be made. The adviser may sensibly take herself to be disagreeing with Jill's earlier conclusion, and Jill, after taking into account the adviser's information, may sensibly retract her earlier belief and acknowledge that she was wrong to believe that she ought to give A.

The picture of advice emerging from this view ascribes to it a dual character. Like other statements, ought-claims in advice are subject to the standard of truth that functions as an ideal for sincere utterances. At the same time, however, advice aims at improving the agent's decision situation, e.g., by providing additional information. Therefore, advice does not just passively represent a certain state of affairs, but actively contributes to its obtaining; it thus might very well cause its own truth. To borrow from Bernard Williams, "advice...has to be understood, in part, in terms of its own intended effects." 27 This certainly is a peculiarity that might need some getting used to, but on reflection I think we have to accept it.

Once we acknowledge that perspectivists have to make a decision about the time at which the evidence counts as relevant, it falls into place that this point should be the time of the action, not that of the judgment. Compare the parallel question in rational choice theory. It seems obvious that the rationality of a choice at a certain point of time $t$ depends on the

${ }^{25}$ Contrast this view with the one that Kolodny and MacFarlane $(2010,118)$ attack: " $S$ ought (at $t$ ) to $\phi$ iff $\phi$-ing is the best choice available to $S$ in the light of what $S$ knows at t." They briefly consider the view I am defending here in their companion paper (unpublished); my adoption and development of it has greatly benefited from their discussion.

${ }^{26}$ Normally, it will be this additional transmittance of evidence, which usually accompanies advice, that will ensure that the ought-claim is true, but it is also possible that the adviser's ought-statement itself provides sufficient evidence for the agent relative to which she ought to do what she is advised to do.

${ }^{27}$ Williams (1995/1989, 42). 
evidence or beliefs that the agent has at $t$, not on the evidence or beliefs the agent has at the time at which that question is considered. Prima facie, I see no reason to suppose that things should be different with respect to what the agent ought to do. Or consider ex post judgments about what an agent ought to have done in the past. It would be against the spirit of perspectivism to think that what the agent ought to have done can depend on information that she might have gained years after she had to make the decision, so it is very natural to say that what she ought to have done depends on the evidence she had when she was supposed to act. But if this is the correct account for ex post judgments, it would be astonishing if it was not the correct account for prospective judgments, too.

Moreover, the view I have suggested not only accommodates second- or third-personal phenomena, such as advice, but can plausibly be motivated from the perspective of the first person as well. For instance, suppose that Jill knows that other people in the room know which treatment $-\mathrm{B}$ or $\mathrm{C}-$ is the cure. In this case, it does not seem appropriate for her to claim confidently, "I ought to give A," but rather to say, "I don't know what I ought to do." 28 While this is what the static view predicts, it would not make much sense on the view that "ought" relates to the agent's current evidence. Or suppose that Jill needs to make the decision tomorrow in order to prevent a serious deterioration of the disease. She may say to herself today: "I believe that I ought to give treatment A, because that is what my evidence suggests now. However, let's see whether I can gather more information until I actually have to make a decision." This thought seems to presuppose that she can correct her belief that she ought to give treatment A on the basis of new information. And, indeed, when Jill learns that treatment $C$ is the cure the next day, she may say to herself, "Yesterday, I thought I ought to give treatment A, but now I know that I was wrong. I ought to give treatment C." If we want these first-personal thoughts to express truths, then we should take oughtstatements to be dependent on the evidence available at the time of the act, not the evidence available at the time of the judgment.

It thus seems that the clarification of perspectivism I am suggesting not only provides an attractive solution to the problem of advice, but also accounts for important first-personal phenomena, and is hence more plausible than its rival for independent reasons. In the remainder of this section, I will defend the view against three objections.

Consider the first objection, which comes from Kolodny and MacFarlane. ${ }^{29}$ Intuitively, an adviser knowing for certain that $\mathrm{C}$ is the cure will conclude directly that Jill ought to give C. But according to static perspectivism, this inference is only justified if the adviser succeeds in improving Jill's evidence. Thoughts about the effects of the advice, however, will appear to the adviser as being beside the point. It thus seems that the view is committed to an implausibly indirect picture of advice.

\footnotetext{
${ }^{28}$ See Björnsson and Finlay $(2010,13)$ for a similar point.

${ }^{29}$ Cf. Kolodny and MacFarlane (unpublished).
} 
I agree that in a normal case, it would be rather peculiar for an adviser to go through considerations about the effectiveness of information transmittance before issuing advice. But I disagree that perspectivism requires any such thing. The view makes a claim about a necessary condition for the truth of ought-judgments; it does not entail anything about what role this condition should play in one's actual considerations. For an analogy, consider the plausible claim that "A ought to $\phi$ " is true only if A is alive. In most situations it would be strangely indirect and beside the point to think about the question of whether $\mathrm{A}$ is a zombie, a robot or a living being before giving him advice. But that of course does not mean that A's being alive is not a necessary condition for the truth of "A ought to $\phi . "$ Rather, that A is alive will normally play a role in the background of one's consideration, perhaps as a dispositional belief. Similarly, thoughts about how one's advice may alter the informational state of the advisee typically will not occur in the foreground of an adviser's considerations. But advice is also typically carried out on the background assumption that it will improve the informational state of the advisee (note that otherwise advice seems pretty much pointless). Perspectivism thus allows for an adviser to conclude that Jill ought to give $\mathrm{C}$ directly from the fact that $\mathrm{C}$ is the cure - the supposition that the advice will alter the agent's information will normally play its role as a background assumption and not in the foreground of the adviser's considerations.

In order to evaluate perspectivism, we should therefore ask whether it provides correct conditions for ought-judgments, not whether these conditions figure in the explicit considerations of advisers (or deliberators). At this point, a second objection by Kolodny and MacFarlane comes into play. They imagine a situation in which the adviser justifiably expects that he will not succeed in transmitting his evidence to the agent, maybe because the agent mistrusts him or is out of earshot. While perspectivism appears to entail that Jill ought to give A in this case, we may think it natural for the adviser to insist that she actually ought to give C. The objection is that perspectivism incorrectly entails that this belief of the adviser would be false.

But I think it is far from obvious that the adviser's belief is true in such a case. Consider, first, the possibility that the adviser is out of earshot: He simply cannot reach the doctor before she has to make a decision. I think that in such a case Jill ought to give treatment $\mathrm{A}$, since every other action would constitute an unacceptable risk in her situation. The adviser will of course regret that he is out of earshot, but on reflection he should agree that Jill ought to give treatment $\mathrm{A}$ in her situation, even though he knows that $\mathrm{C}$ is the cure. ${ }^{30}$

In the second case, the adviser is within earshot, but he anticipates that the agent does not trust him. This case is more interesting. As I see

${ }^{30}$ Kolodny and MacFarlane (unpublished) seem to acknowledge this point later, when stating that the agent's evidence can be the relevant parameter in contexts in which advice is impossible. Note that the adviser can still truly believe that the doctor ought to give $\mathrm{C}$ in some qualified sense that is not at issue here, e.g., he may truly believe that the doctor ought to give $\mathrm{C}$ relative to all facts. 
it, we should distinguish the case in which the agent's mistrust is justified from the case in which it is not. If Jill is not justified in mistrusting the adviser, then it is true, on the suggested account, that she ought to give C. For her mistrusting the adviser constitutes a failure to take into account the evidence that is available to her in the relevant sense: If she were using her rational capacities appropriately, she would come to believe that $\mathrm{C}$ is the cure. Hence, contrary to what Kolodny and MacFarlane maintain, perspectivism actually predicts that in such a case, the adviser can truly say, "You ought to give C."

Things look different if the agent's suspicion is justified. Under such circumstances, Jill does not have sufficient evidence that $\mathrm{C}$ is the cure, and perspectivism therefore predicts that an adviser's statement, "You ought to give C," is indeed false. Again, on reflection it seems to me that this implication is correct. If Jill justifiably mistrusts the adviser, then deciding on his advice to give the treatment that may well kill the patient seems clearly too risky. Jill ought to give A in these circumstances, and this is what perspectivism tells her to do. The adviser, in turn, will find it unfortunate that the situation is such that his advice cannot justifiably be trusted, but on reflection he should acknowledge that Jill ought to give A in such a situation.

Let me turn to the third objection. Suppose that a fully informed bystander voluntarily refuses to share his information with Jill. Perspectivism here implies that the bystander could truly say, "You ought to give A," even though he knows that C is the cure - and this seems counterintuitive. ${ }^{31}$ I agree that something is wrong with that statement, but what is wrong, I maintain, is not that it is literally false. Again, I think it is plausible that Jill really ought to give $\mathrm{A}$ if the bystander withholds his information, for it would clearly be too risky for her to do anything else as long as she lacks better information. So what is wrong with the bystander's statement, then? Note that the bystander could also truly say, "You ought to give C," if he gave up his refusal to share the evidence. Note also that what he ought to do, relative to his evidence, is make the second statement rather than the first, so here we already have a clear sense of what is wrong with his statement. But there is also a pragmatic explanation of why his statement seems wrong. This explanation is based on an assumption that will be further explored in section VI, namely that agents have a general interest in grounding their deliberative conclusions in better information rather than worse information. Given this, it seems plausible that statements of the form, "A ought to $\phi$," generally carry the implicature that they are based on the best information that can be made available to the agent. And this implicature is, of course, false when the bystander states, "You ought to give A," even though he knows that $\mathrm{C}$ is the cure. Hence, what is wrong with the bystander's statement is that it carries a false implicature, not that it is literally false.

31 Thanks to an anonymous referee for JESP for both pressing this objection and suggesting a reply to it. 
To sum up, neither objection poses an actual problem for perspectivism. Pace Kolodny and MacFarlane, it does not require an implausibly indirect account of an adviser's considerations. Moreover, the static view distinguishes with subtlety between different kinds of cases in which a better-informed bystander anticipates that he cannot transmit the evidence to the agent, or refuses to do so voluntarily.

\section{The Problem of Sharing and Seeking New Evidence}

The case of advice, however, raises another question that perspectivists have difficulties answering: Why should an adviser with better information bother to share his information with an advisee? According to static perspectivism, by transmitting his evidence to Jill the adviser makes it true, as it were, that she ought to give C. If, on the contrary, the adviser withholds his information, then it is true that the doctor ought to give A, because that is what her evidence will suggest at the time of her action. But if deliberation seeks to answer the question, "What should I do?" and advice seeks to help answering that very question, then it seems hard to explain why sharing the information counts as belping the agent. After all, withholding the information would make it just as easy - if not easier for the agent to find a true (albeit different) answer to the question both are trying to answer. ${ }^{32}$

Let me be clear about what is, and what is not, the question that poses a problem for perspectivism. The problem is not to answer the question: Why ought the adviser to share the information? According to perspectivism, the adviser ought to share the information for example because he has evidence that sharing the information will lead to the cure of the patient. The question is: Why would the adviser's sharing his information count as advice, as helping to find a correct answer to the agent's deliberative question? This question provides a serious challenge for perspectivism, for if the truth of an answer to the deliberative question is relative to whatever evidence the doctor happens to have at the time of her action, how can improving that evidence contribute to finding a correct answer?

Even worse for perspectivism, a similar question arises even in the absence of an adviser, from the perspective of the first person alone. It seems that when deliberating about what to do, agents sometimes seek evidence that is not yet available to them. Again, the problem is not to explain why agents sometimes ought to seek new evidence. According to perspectivism, one ought to seek evidence just when one's evidence suggests that one ought to seek evidence. What remains unexplained is why an agent's looking for better evidence can contribute to finding an answer to her deliberative question. According to perspectivism, the occurrence of new evidence changes what the agent ought to do. But if that is so, how

\footnotetext{
32 Compare Björnsson and Finlay (2010, 14-16) for a discussion of a similar question that can be directed at their contextualist view. They argue that, despite appearances, Kolodny and MacFarlane's relativist account faces the same difficulty.
} 
can seeking new evidence contribute to finding out what the agent ought to do? If what the agent ought to do depends on the evidence that she happens to have at the time of the action, then it seems that she could just as well do nothing or even destroy available evidence - indeed this could be very helpful in coming to a clear-cut deliberative conclusion!

Let me start with the first-personal problem: How can seeking new evidence contribute to finding out what one ought to do? Objectivism has a straightforward answer to that question: It will normally bring one closer to what one objectively ought to do. But we have rejected objectivism above, so we need an alternative answer to that question. On the face of it, the question seems perfectly legitimate, and perspectivism cannot make sense of it. Consider Jill again, this time on the eve of her decision. She asks herself, "What ought I to do tomorrow? Give A? Or go for B or C?" The evidence available to her now suggests giving treatment $A$, and if she does not seek more evidence, that is also what her evidence will suggest tomorrow. But suppose that if she put a lot of effort into researching new evidence that night, then tomorrow she would have sufficient evidence to give $\mathrm{C}$ and really cure the patient of his disease. Why ought she to seek this evidence? Perspectivists can answer this question: Presumably, her evidence now suggests that by seeking evidence she could make her patient's life significantly better. So far, so good. It seems, though, that we want to say more. We want to say that, if Jill really spends all night seeking evidence, she could perfectly well understand herself not only as doing what she now ought to do (namely, seeking evidence), but also as making an effort to find out what treatment she ought to give tomorrow. And this is puzzling for static perspectivism, which maintains that what treatment she ought to give tomorrow depends on what her evidence will suggest tomorrow, whether she will have sought further evidence or not.

The problem, then, seems to be that the view makes "ought" dependent on the evidence the agent will bappen to have, instead of the best evidence, or the evidence that the agent could have under favorable circumstances. If what treatment the doctor ought to give depended on the best evidence she could have tomorrow, then we would have an explanation for why seeking more evidence can be a way of finding out what one ought to do. However, it seems too strong - and against the spirit of perspectivism - to say that what one ought to do depends on the best evidence that one could come to have at the time of the action. Suppose that Jill's evidence on the eve of her decision strongly suggests seeking new evidence in the library by going through various medical journals. In fact, she cannot find any new evidence in these journals, but she could find evidence if she were to call a former colleague who, unbeknownst to her, just discovered the relevant information days ago. So if what treatment Jill ought to give tomorrow depends on the best evidence she could come to have by tomorrow, then it is true that she ought to give C. But if she does what her evidence suggests she do all along the way, then she will never have the best evidence that she could have, and she will never be in the position to responsibly give treatment C. It is against the spirit of perspectivism that these counterfactual truths can influence what Jill 
ought to do, independently of any evidence that was ever really available to her.

\section{Ought and Time (ii)}

What I suggest instead is that "ought" is relative to the evidence that the agent would have, if she were seeking evidence as she ought to. Or more exactly:

Dynamic perspectivism: A ought (at $\mathrm{t}_{1}$ ) to $\phi$ at $\mathrm{t}_{2}$ if, and only if, A ought (at $\mathrm{t}_{1}$ ) to $\phi$ at $\mathrm{t}_{2}$ relative to the evidence that would be available to $\mathrm{A}$ at $\mathrm{t}_{2}$ if $\mathrm{A}$ were seeking evidence from $t_{1}$ until $t_{2}$ as $A$ ought (at every $t$ between $t_{1}$ and $t_{2}$ ) to.

Jill, on the eve of her decision, deliberates about what treatment to give. What treatment she ought to give does not depend on the evidence that she will happen to have, no matter what she does until tomorrow, but rather on the evidence that she would have if, from now on, she sought evidence as she ought to. This explains why we can understand her seeking evidence not only as doing something that she ought to do right now, but also as a way of finding out what she ought to do tomorrow.

We can call this view "dynamic," to contrast it with the static view from section III, because it allows for the same utterance, e.g., "Jill ought to give A at t," to be true when uttered at one point in time, but false at another. This is because the dynamic view contains a contextualist element that relativizes ought-statements to a certain time, which might be different from the time of the action. Suppose, for example, that Jill has to make a decision tomorrow afternoon $\left(a t t_{3}\right)$. At the eve of her decision (at $t_{1}$ ), her evidence suggests giving $A$ tomorrow (at $t_{3}$ ), but also seeking further evidence now, and seeking further evidence would in fact reveal to her, by $t_{3}$, that $C$ is the cure. In such a case, the dynamic view implies that Jill ought (at $t_{1}$ ) to give treatment $C$ at $t_{3}$. But suppose that, contrary to what her evidence suggests, Jill does not seek further evidence. On the next morning (at $\mathrm{t}_{2}$ ), she wakes up and asks herself again what treatment she ought to give at $t_{3}$. Now assume that her evidence no longer suggests seeking further evidence. Suppose that if Jill started to seek evidence now $\left(\right.$ at $t_{2}$ ), this would no longer lead her to improve her evidence until $t_{3}-$ simply because in order to find better evidence, she would need more time than she has until $t_{3}$. The dynamic view will then imply that Jill ought $\left(\right.$ at $\left.t_{2}\right)$ to give treatment $A$ at $t_{3}$ - again, because this is what her evidence at $t_{3}$ would suggest if she were seeking evidence from $t_{2}$ to $t_{3}$ as she ought to. Hence, the dynamic view entails some fluctuation of what Jill ought to do at $t_{3}$. At $t_{1}$, she ought to give $C$ at $t_{3}$; while at $t_{2}$ and $t_{3}$, she ought to give $\mathrm{A}$ at $\mathrm{t}_{3}$. Generally speaking, the truth of any claim that $\mathrm{A}$ ought to do something at some later point in time may vary from one earlier point in time to another, depending on the actual evidence the agent has at these earlier points in time.

The idea that ought-statements implicitly refer to two points in time - a time at which the action is supposed to take place and a time at which the requirement is supposed to hold - is not new; it can, and has been, 
defended independently of the question of perspective dependence. ${ }^{33}$ It might be argued that because of this contextualist element, the dynamic view entails a form of relativism similar to the one that it was supposed to avoid. As I see it, however, the view is not relativist in a problematic sense. I believe that "A ought to $\phi$ " is like "A has a new haircut." At any particular time, these statements are true or false independently of the speaker or the assessor. But, of course, "A has a new haircut" may be true today and false in two months. There does not seem to be any worrying relativism involved here; similarly, I do not think that we should worry in the case of ought-statements.

Or consider a similar claim in the domain of normative reasons. If I promise you on Tuesday to help you move on Wednesday, this plausibly gives me a reason to help you on Wednesday, which I did not have before. Hence, on Monday the statement, "I have a reason to help you on Wednesday," was false, while on Tuesday it was true. In order to avoid contradiction, we need to take this statement to express a proposition which is relativized to the time at which the reason holds, which is different from the time at which the action is supposed to take place. But there is nothing worryingly relativistic going on; in particular whether or not the reason statement is true does not depend on the speaker or the assessor.

Nevertheless, the relativization of ought-statements to time raises the question of why the dynamic view should not be vulnerable to the disagreement-related objections that have been brought forward against views that relativize ought-statements to the bodies of information of different speakers (discussed above). On a simple application of the dynamic view, an agent's utterance, "I ought to $\phi$," and an adviser's utterance, "No! You ought not to $\phi$," made at a slightly later time, would indeed have to be relativized to different points in time, with the result that they could not be taken to express a genuine disagreement. But as in the case of "A has a new haircut," it seems very natural to suppose that "A ought to $\phi$ " relativizes to a period of time rather than a single point. And as people can of course disagree - within a certain period of time - about whether A has a new haircut, so they can disagree about whether A ought to $\phi$, as long as the "ought" refers to the same period.

But does the dynamic view not face a regress? According to it, whether you ought to $\phi$ depends on whether the evidence that you ought to seek suggests $\phi$-ing. But then, whether you ought to seek evidence should also depend on whether the evidence that you ought to seek suggests seeking evidence, etc. ad infinitum. In making one "ought" dependent on another "ought," it seems that the dynamic view suggests an infinite dependence relation that is hard to make sense of.

In fact, however, there is no such regress problem. According to dynamic perspectivism, what an agent ought to do later depends (in part) on whether and how the agent ought to seek evidence now. But when we

${ }^{33}$ See, e.g., Zimmerman (2008, 127-28, and esp. 151-68). Cf. also Prichard (2002b). 
consider whether and how the agent ought to seek evidence now, then $t_{1}$ and $t_{2}$ fall into one, and there is no difference between the evidence that would be available if one were looking for it between $t_{1}$ and $t_{2}$ and the evidence that actually is available. Let me illustrate this point by considering Jill on the eve of her decision, again. What she ought to do tomorrow depends, according to the dynamic view, on the evidence that would be available to her tomorrow if she were seeking evidence from now on as she ought to from now on. At this point, the danger of regress emerges: On what does it depend whether and how Jill ought to seek evidence now? Applying the view literally, we get the result that it depends on the evidence that would be available to her if she were seeking evidence from now to now as she ought to from now to now. However, the evidence that would be available to Jill if she were seeking evidence from now to now as she ought to just is the evidence available to her now. We can cancel out the counterfactual condition involving the interval for seeking further evidence whenever we consider what someone ought to do now. Therefore, the regress stops. Jill can ask herself, "Ought I to seek more evidence now and if so how?" and the answer will just depend on what her current evidence suggests. However, we are now in a position to understand her seeking evidence not only as something that she ought to do because her current evidence suggests it, but also as a way of finding out what she ought to do tomorrow.

Finally, it might seem that introducing the dynamic view is simply an ad hoc move to solve the problems of perspectivism. But I think it is a natural advancement of perspectivism, and it can also be given an independent rationale. In the discussion of the static view, I have argued that when considering what an agent ought to do at a certain point in time there are independent reasons to take as relevant the evidence at the time of the action rather than the evidence at the time of the ought-judgment. Starting from this view, we can determine what would be an optimal strategy concerning what to do from a certain point in time forward:

Optimal strategy: At $\mathrm{t}_{1}, \mathrm{O}$ is an optimal strategy concerning what to do from $\mathrm{t}_{1}$ forward if, and only if, for every time $t$ from $t_{1}$ forward, if $A$ were to carry out $O$, then, at $\mathrm{t}$, A would be doing what she ought to do relative to the evidence available to $\mathrm{A}$ at $\mathrm{t}$.

Next, consider the following plausible principle:

Strategical "ought": At $\mathrm{t}_{1}, \mathrm{~A}$ ought to $\phi$ at $\mathrm{t}_{2}$ if, and only if, $\phi$-ing at $\mathrm{t}_{2}$ is involved in every optimal strategy concerning what to do from $t_{1}$ forward.

Together, optimal strategy and strategical "ought" entail dynamic perspectivism. Hence, if we combine the static view from section III with the natural idea of an optimal strategy concerning what to do from a certain point in time forward, and with a plausible account of "oughts" concerning future 
actions, we get the dynamic view that I have been defending in this section. $^{34}$

\section{Sharing Evidence and the Good}

While dynamic perspectivism thus presents an attractive solution to the problem of seeking evidence, it is not much help regarding the problem of sharing evidence as it is posed from the perspective of an adviser. The dynamic view accounts for the idea that Jill can understand her seeking new evidence as a way of finding out what treatment she ought to give, because what treatment she ought to give does not depend on the evidence she will happen to have, but on the evidence she will have if she seeks for evidence as she ought to. But this cannot explain why an adviser can understand his sharing of information as a way of helping Jill to find out what she ought to do, since what Jill's evidence would suggest if she sought for evidence as she ought to may still be different from what the adviser's better evidence suggests. We still need an explanation of how sharing this evidence can count as helping to answer a question that could just as well be answered correctly (albeit differently) in the absence of any advice.

The problem, I believe, cannot be solved by further revising of perspectivism, but only by reconsidering the picture of advice and deliberation that it presupposes. The key is to remind ourselves that we haven't denied that perspective-independent normative or evaluative considerations play any role in deliberation. The argument against objectivism establishes that the "ought" of deliberative conclusions depends on perspective, but this does not imply that reaching such conclusions is the one and only concern of deliberative agency. On the contrary, it is quite plausible that agents in their deliberation are also concerned with promoting, protecting or respecting certain values. As Björnsson and Finlay argue, better information puts agents in a better position to pursue these values, which explains why rational agents have a general interest in basing their deliberative conclusions on better information. ${ }^{35}$ In sharing evidence, then, advisers do not literally help agents to find a true answer to their question, "What should I do?" but they nevertheless respond to a fundamental concern of deliberative agency: the pursuit of certain values and the resulting interest in better information.

34 Full credit for this suggestion goes to an anonymous referee for JESP. Strategical "ought" could be called a "possibilist" account of "oughts" concerning future actions. The debate between possibilists and actualists lies beyond the scope of this paper, but see Zimmerman (2008, 119-25) for an excellent discussion.

35 See Björnsson and Finlay $(2010,16)$, in defense of their contextualist view. I make use of their idea for perspectivism here, but adopt neither their speaker relativism, nor the more or less consequentialist assumption that "ought" has to be understood in terms of greatest expected value, nor the claim that the agent's interest in reaching true oughtjudgments is merely instrumental. It is difficult to say something about the relation between "good" and "ought" while remaining neutral with respect to certain substantial issues in moral theory, but it is probably safe to say that one ought to take the option with the greatest expected value in case one has no stronger reason not to take it. 
What this means is that the objective good, though not directly providing the "ought" of deliberative conclusions, still functions as an evaluative ideal that we strive for in practical deliberation. ${ }^{36}$ The air of paradox is only apparent, as the case of belief shows. Objective truth functions as an ideal in theoretical deliberation, but it does not settle directly what we ought to believe. As a conscientious believer, I aspire to believe the truth, even though this is not what I ought to believe without qualification. When I know that a fair coin has landed, but I do not know how, it seems that I ought not believe it landed heads, and I ought not believe it landed tails. ${ }^{37}$ Believing either proposition, without having evidence supporting one proposition rather than the other, seems to involve not taking truth seriously. What this shows is that maintaining the ideal of objective truth is compatible with following an evidence-relative "ought" rather than an objective one - indeed, it even seems that taking truth seriously, here, requires one to form one's beliefs in accordance with the evidence rather than with the facts. Truth functions as an evaluative ideal in believing, but it does not directly settle what we ought to believe. Similarly, Jill will give the treatment that is suggested by her evidence, partly because she is concerned with the objective well-being of her patient. Again, what is objectively good functions as an ideal in deliberation, even though it does not directly settle what we ultimately ought to do. Advisers can thus understand their sharing of evidence as a response to the deliberative concerns of the agent without assuming that they are helping to answer the more specific question, "What ought I to do?"

\section{Conclusion}

Let me conclude by way of a summary. In section I, I have considered an objection to objectivism that I think is fatal to this view. We had to reject objectivism in order to preserve the truth of:

(a) An agent believing the correct view about "ought" can rationally avoid taking a 50 percent risk of killing someone in order to have a 50 percent chance of avoiding a minor complaint.

I turned to perspectivism in section II, considering cases of advice. We wanted to say:

(b) An adviser can correctly advise an agent to do what the adviser's better evidence suggests, thereby answering the agent's deliberative question, "What ought I to do?"

\footnotetext{
${ }^{36}$ See Oddie and Menzies $(1992,513)$ for the thesis that "the correct regulative ideal for the moral agent is that of maximizing objective value." Putting aside questions of value maximization, I take it that this view (which Oddie and Menzies call objectivism) is compatible with the rejection of the objective view that is under discussion here.

${ }^{37}$ I borrow this example from Gibbard $(2005,340)$.
} 
In section III, I have presented, defended against objections and motivated independently the idea that "ought" is relative to the agent's evidence at the time of the action rather than the time of the judgment, which allows for the truth of (b). However, two further problems with this suggestion appeared. Intuitively, we wanted to say:

(c) Seeking evidence not yet available to oneself might be a way for an agent to find an answer to her deliberative question, "What ought I to do?"

(d) Sharing evidence otherwise unavailable to an agent might be a way for an adviser to help the agent find an answer to her deliberative question, "What ought I to do?”

As we have seen in section IV, both (c) and (d) cannot be explained by a view that takes the "ought" in the deliberative question to simply depend on the evidence that happens to be available to an agent at the time of the action. In section $\mathrm{V}$, I have defended a version of perspectivism that instead takes it to depend on the evidence that the agent will have at the time of her action, if until that time she seeks evidence as she ought to. This can explain why (c) is true, but it cannot explain why (d) is true. As far as I can see, we cannot preserve the spirit of perspectivism while holding that (d) is literally true. But as I have argued in section VI, we can hold something similar to (d), namely:

(d)* Sharing evidence not yet available to an agent might be a way of helping the agent to respond to her deliberative concerns.

The truth of (d)* can explain the most significant part of the problem of sharing evidence. It can explain why sharing evidence can count as helping the agent in her deliberation. But ultimately, we must deny that it can count as helping the agent to find an answer to the more specific question of what she ought to do. This is a bullet not too hard to bite, I think. Sharing information in advice helps the agent insofar as it brings her into a better position to pursue her values and concerns. In this respect, advice responds to the evaluative ideal of deliberation rather than to its deontic focus. $^{38}$

\footnotetext{
${ }^{38}$ For comments on earlier versions of this paper, I am grateful to Vuko Andric, Katrin Beushausen, Tony Bezsylko, Krister Bykvist, Luis Cheng-Guajardo, Guido Ehrhardt, Christoph Fehige, Steve Finlay, Daniel Friedrich, Jan Gertken, Tim Henning, Frank Jackson, Felix Koch, Niko Kolodny, Andreas Müller, Katrien Schaubroeck, Thomas Schmidt, Karsten Schoellner, Jay Wallace and two anonymous referees for JESP. The paper has also greatly benefited from discussions at the XXII. Deutscher Kongress für Philosophie, Ludwig-Maximilians-Universität München, as well as colloquia and seminars at Humboldt-Universität zu Berlin; Universität des Saarlandes, Saarbrücken; University of California, Berkeley; and University of Oxford, where I had the chance to present parts of the material. Work on this paper has been supported by the Studienstiftung des deutschen Volkes and the Deutsche Forschungsgemeinschaft (SFB 644).
} 
Benjamin Kiesewetter

Humboldt-University Berlin

Department of Philosophy

benjamin.kiesewetter[at]philosophie.hu-berlin.de 


\section{References}

Andric, Vuko (forthcoming). "Objective Consequentialism and the Licensing Dilemma." Philosophical Studies.

Arpaly, Nomy (2000). “On Acting Rationally Against One’s Best Judgment." Ethics 110(3): 488-513.

Björnsson, Gunnar and Finlay, Stephen (2010). "Metaethical Contextualism Defended." Ethics 121: 7-36.

Broome, John. "Rationality Through Reasoning." Unpublished book manuscript.

Bykvist, Krister. "How to Do Wrong Knowingly and Get Away with It." Unpublished manuscript.

Coates, Allen (forthcoming). "The Enkratic Requirement." European Journal of Philosophy.

Dancy, Jonathan (2000). Practical Reality. New York: Oxford University Press.

Davidson, Donald (1980/1969). "How Is Weakness of the Will Possible?" In Essays on Actions and Events. Oxford: Clarendon Press, pp. 21-42.

Ewing, A. C. (1947). The Definition of Good. New York: Macmillan.

Feldman, Richard (1988). "Subjective and Objective Justification in Ethics and Epistemology." The Monist 71(3): 405-19.

Gibbard, Allan (2005). "Truth and Correct Belief." Philosophical Issues 15(1): 338-50.

Gibbons, John (2010). “Things That Make Things Reasonable.” Philosophy and Phenomenological Research 81(2): 335-61.

Graham, Peter A. (2010). "In Defense of Objectivism about Moral Obligation." Ethics 121(1): 88-115.

Henning, Tim. “Normative Reasons, Oughts, and Contexts.” Unpublished manuscript.

Jackson, Frank (1991). "Decision-theoretic Consequentialism and the Nearest and Dearest Objection." Ethics 101(3): 461-82.

Kolodny, Niko (2005). "Why Be Rational?” Mind 114(455): 509-63.

Kolodny, Niko and MacFarlane, John (2010). "Ifs and Oughts." The Journal of Philosophy 107(3): 115-43.

"Ought: Between Objective and Subjective." Unpublished manuscript.

Korsgaard, Christine M. (1986). "Skepticism about Practical Reason." The Journal of Philosophy 83(1): 5-25.

Moore, G. E. (1969/1912). Ethics. Oxford: Oxford University Press.

Oddie, Graham and Menzies, Peter (1992). "An Objectivist's Guide to Subjective Value." Ethics 102(3): 512-33.

Parfit, Derek (2011). On What Matters. Vol. 1. New York: Oxford University Press.

Prichard, H. A. (2002a/1932). "Duty and Ignorance of Fact." In Moral Writings. Oxford: Clarendon Press, pp. 84-101.

(2002b). "The Time of an Obligation." In Moral Writings. Oxford: Clarendon Press, pp. 268-69.

Raz, Joseph (1999/1975). Practical Reason and Norms. Second edition. New York: Oxford University Press.

Regan, Donald (1980). Utilitarianism and Co-Operation. New York: Oxford University Press.

Robertson, Simon (2011). "Epistemic Constraints on Practical Normativity." Synthese 181: 81-106.

Ross, Jacob (2006). Acceptance and Practical Reason. PhD dissertation, Rutgers University.

(forthcoming). "Rationality, Normativity, and Commitment." Oxford Studies in Metaethics.

Ross, W. David (1968/1939). Foundations of Ethics. Oxford: Clarendon Press.

Scanlon, T. M. (1998). What We Owe to Each Other. Cambridge, MA: Harvard University Press.

(2008). Moral Dimensions: Permissibility, Meaning, Blame. Cambridge, MA: Harvard University Press.

Schroeder, Mark (2009). "Means-end Coherence, Stringency, and Subjective Reasons." Philosophical Studies 143(2): 223-48.

Smith, Michael (1994). The Moral Problem. Oxford: Blackwell. 
(2008). "Consequentialism and the Nearest and Dearest Objection." In Minds, Ethics, and Conditionals: Themes from the Philosophy of Frank Jackson, Ian Ravenscroft, ed. Oxford: Clarendon Press, pp. 237-66.

Thomson, Judith Jarvis (1986/1983). "Imposing Risks." In Rights, Restitution, and Risk. Cambridge, MA: Harvard University Press, pp. 173-91.

2008. Normativity. Chicago and La Salle: Open Court.

Wedgwood, Ralph. 2003. "Choosing Rationally and Choosing Correctly." In Weakness of Will and Practical Irrationality, eds. Sarah Stroud and Christine Tappolet. New York: Oxford University Press, pp. 201-29.

Williams, Bernard (1981a/1979). "Internal and External Reasons." In Moral Luck. Cambridge: Cambridge University Press, pp. 101-13.

(1981b). "Ought and Moral Obligation.” In Moral Luck. Cambridge: Cambridge University Press, pp. 114-23.

(1995/1989). "Internal Reasons and the Obscurity of Blame." In Making Sense of Humanity. Cambridge: Cambridge University Press, pp. 35-45.

Zimmerman, Michael J. (2008). Living with Uncertainty: The Moral Significance of Ignorance. Cambridge: Cambridge University Press. 